\title{
DON QUIJOTE COMO SILENO: \\ ¿UNA PISTA PARA DESCIFRAR LAS INTENCIONES DE CERVANTES?
}

Tras la ignominiosa paliza que recibe don Quijote a manos de los «desalmados yangüeses» en el capítulo XV de la Primera Parte, y a la vista de la lastimosa condición de Rocinante, nuestro protagonista pide que Sancho le suba encima de su asno para seguir adelante su camino. Al hacerlo, don Quijote puntualiza lo siguiente:

«... esa bestezuela podrá suplir ahora la falta de Rocinante, llevándome a mí desde aquí a algún castillo donde sea curado de mis feridas. Y más, que no tendré a deshonra la tal caballería, porque me acuerdo haber leído que aquel buen viejo Sileno, ayo y pedagogo del alegre dios de la risa, cuando entró en la ciudad de las cien puertas iba, muy a su placer, caballero sobre un muy hermoso asno" ${ }^{1}$.

Resulta un tanto desconcertante la comparación que el mismo don Quijote establece. En ningún momento de la obra se muestra dispuesto a admitir su propia condición «risible»; más bien, todo lo contrario ${ }^{2}$. Si bien no se compara aquí con el mismo «alegre dios de la risa" (o sea, Dionisio o Baco), sí se compara con el maestro de éste, el viejo Sileno.

Las notas dedicadas a esclarecer este pasaje suelen centrarse en la identificación del «alegre dios de la risa» y en señalar que don Quijote confunde la ciudad de Tebas en Beocia, patria de Dionisio,

1 Miguel De Cervantes, El ingenioso hidalgo don Quijote de la Mancha, t. I, ed. LuIS A. MuriLlo. Madrid, Castalia, 1978, p. 196. (Todas las citas posteriores del Quijote provienen de esta edición.)

2 Basten como botones de muestra su reacción a la risa de las dos prostitutas sentadas en la puerta de la venta (I, 2, p. 83) y a la de Sancho tras la aventura de los batanes (I, 20, pp. 248-49). 
por la de Egipto (que tenía cien puertas, según los antiguos). La atención dedicada a la figura de Sileno se reduce fundamentalmente a referencias a pasajes de Ovidio, Virgilio y Horacio donde ésta aparece ${ }^{3}$

Es una pena que no se haya explorado más este vínculo que don Quijote forja con este ser legendario. Tómese en cuenta que, para él, el antecedente de Sileno es suficiente para justificar su empleo del asno para servirle de transporte en estas desdichadas circunstancias. Es decir, su actitud hacia Sileno es plenamente favorable.

En las páginas que siguen examinaré las ramificaciones de la auto-asociación de don Quijote con Sileno. Entre otras cosas, trataré de mostrar que la comparación es una pista importantísima para comprender cómo Cervantes quiere que descifremos su obra. Es más: propondré que características fundamentales de su protagonista pueden haberse basado en el modelo de Sileno.

Como ocurre tantas veces con las figuras mitológicas de la Antigüedad clásica, hay muchas versiones sobre los orígenes de Sileno. Para algunos autores, su padre fue Pan y para otros Hermes. Su madre puede haber sido la misma Tierra ${ }^{4}$. Entre los relatos sobre el lugar de su nacimiento y su crianza, uno afirma que se crió en las laderas del Monte Nysa, como sucedió en el caso de su hijo adoptivo, Dionisio ${ }^{5}$. Otros colocan sus orígenes en Frigia (o sea, en la zona septentrional de la Asia Menor). Estudiosos recientes tienden a apoyar esta última versión, señalando que el término se aplicaba en esa región a un tipo de divinidad rural con rasgos equinos (por ejemplo, una cola). Muy pronto comenzó su lazo estrecho con los sátiros, grupo con el cual los silenos muchas veces se confundían. Esto ocurrió a pesar del hecho de que los rasgos animales en el caso de los sátiros se derivaban de la cabra y no del caballo ${ }^{6}$.

De ser toda una categoría de seres semi-divinos, "sileno» pasó a designar a un sujeto individual —o sea, "Sileno» con mayúscula-

\footnotetext{
3 Véanse, por ejemplo, la nota 18 de la edición de Murillo (I, 15, p. 196); la nota 34 de DiEgo Clemencín (ed.), El ingenioso hidalgo don Quijote de la Mancha, t. III (Valencia, Editorial Alfredo Ortells, 1986), pp. 1150-1151; la nota, correspondiente a la línea 190 del capítulo 15, de VICENTE GAOS (ed.), El ingenioso hidalgo don Quijote de la Mancha, t. I (Madrid, Gredos, 1987), p. 302; y la nota 50 de la edición coordinada por FRANCISCO RICo, El ingenioso hidalgo don Quijote de la Mancha, t. I, 2. ${ }^{\mathrm{a}}$ ed. (Barcelona, Instituto Cervantes/Editorial Crítica, 1998), p. 166; además, la nota 166.50 del t. II de la misma edición (p. 315).

4 Consúltense la New Larousse Encyclopedia of Mythology, 2. ${ }^{\mathrm{a}}$ ed., trad. R. ALDington y D. AMES (Londres, Hamlyn, 1970), p. 161; MichaEl GRANT y JOHN HAzEL, Who's Who in Classical Mythology (Londres, Weidenfeld and Nicolson, 1973), p. 366.

5 Véase EdWARD TRIPP, Crowell's Handbook of Classical Mythology (Nueva York, Thomas Y. Crowell Co., 1970), p. 524.

6 Para los puntos que acabo de comentar, consúltese la New Larousse..., p. 161.
} 
aunque con atributos variables y con un historial variopinto y a veces contradictorio ${ }^{7}$. Su papel más o menos inalterable en el rico cuerpo de historias donde figura es, justamente, su papel de tutor o "ayo" del joven Dionisio. En efecto, es gracias a Sileno que Dionisio desarrolla las virtudes necesarias para poder descubrir la magia de la uva fermentada y el arte de cultivar la vid ${ }^{8}$. Es decir, en la medida en que Dionisio se convierte en el dios del vino y el "santo patrón» de la ebriedad - y por tanto, de la risa- es justamente debido a los buenos oficios de Sileno.

De tutor, Sileno pasa a ser el acompañante inseparable de su discípulo, formando parte - junto con los sátiros y ménadas- de su característico séquito en sus largos viajes por el mundo del mito. Tanto en las historias que se cuentan sobre él como en la rica tradición iconográfica, Sileno se presenta como viejo, borracho, pletórico de carcajadas y sentado, claro está, sobre su insustituible asno. Pero aparte de estas cualidades menos respetables, Sileno ostenta otra: sigue siendo un destacado sabio (recuérdese el nexo con Hermes), a veces con capacidad profética o con enormes conocimientos sobre el pasado del mundo ${ }^{9}$.

La proyección cómica de Sileno le gana otro papel prominente en la cultura de la Antigüedad clásica. En las comedias de sátiros del teatro antiguo aparece Sileno como el líder del coro de los sátiros, quienes se refieren a él como "padre». En el Cíclope de Eurípides, por ejemplo, aparece como el risible rehén, junto con sus hijos sátiros, de Polifemo - contentísimo cuando llega Odiseo con cueros de vino ${ }^{10}$ - En la Antigüedad griega tardía, Sileno acompaña al dios Comus en las fiestas públicas, debidamente rodeados, los dos, de alegres beodos ${ }^{11}$.

El nexo con lo cómico, y con el género cómico, se refuerza metonímicamente a través del animal que le sirve de montura a Sileno. Cuando el asno aparece en las representaciones plásticas de Dionisio, se destaca invariablemente su carácter cómico. Siempre va tambaleándose, a punto de caerse. El nexo del asno con el gé-

\footnotetext{
7 Habría que tomar en cuenta que la forma plural - sileni- nunca desaparece del todo.

$8 \quad$ Véase la New Larousse..., p. 158.

9 Para esta compleja combinación de características, consúltese la New Larousse..., p. 161; sobre la inevitable conexión con el asno en representaciones plásticas (jarrones y mosaicos), véase YVES BonNefoY, Mythologies, trad. G. HoNIGSBLUM (Chicago, University of Chicago Press, 1991), t. I, p. 432.

10 He manejado la traducción al inglés de esta obra en Whitney J. OATES y Eugene O'NeILl, Jr. (eds.), The Complete Greek Drama, t. II (Nueva York, Random House, 1938), pp. 391-420. Su ferviente elogio del vino se encuentra en la p. 401.

11 Consúltese JoËL SCHMIDT, Larousse Greek and Roman Mythology (Nueva York, McGraw-Hill Book Company, 1980), p. 69.
} 
nero cómico se confirma por su presencia en Las ranas de Aristófanes, una obra en la que Dionisio mismo es el protagonista. Su esclavo y sirviente, Xanthias, viaja encima de un asno con quien se identifica estrechamente ${ }^{12}$.

Es más: el asno aparece, en los Misterios del culto de Dionisio, como símbolo del adorador ya iniciado o a punto de serlo. Gracias a Dionisio el humilde y feo asno adquiere una bella voz humana; el iniciado, a su vez, trasciende su bestialidad material por la intervención de este dios. De hecho, al iniciado en los Misterios se le denominaba onos (o sea, «asno») ${ }^{13}$

Cuánta de esta riquísima tradición puede haber conocido Cervantes es una incógnita. Casi seguramente conocería su papel en la historia del rey Midas en el Libro XI de las Metamorfosis de Ovidio; también, el que desempeña en la Egloga VI de Virgilio, donde cuenta historias fabulosas sobre el pasado del mundo tras haber sido capturado por dos pastores. Dada la rica tradición iconográfica que rodea a Sileno, es muy posible que Cervantes se hubiera topado más de una vez con su inconfundible figura, que incluiría su montura asnal. Hay esporádicas referencias a Sileno entre los humanistas de la época (incluyendo a Erasmo, como se verá más adelante). Lo que me hace sospechar que sí tendría algún conocimiento relativamente detallado es la estrecha correspondencia que hay entre tantos aspectos de las leyendas que rodean a Sileno y el mismo don Quijote.

Para comenzar, pensemos en la fundamental condición de lococuerdo que caracteriza a don Quijote y que sirve de fuerza motriz de toda la obra. La locura de don Quijote y el comportamiento que suscita se asemejan mucho a una especie de ebriedad ${ }^{14}$. Recordemos que cuando sale en sus andanzas, lleva un lanzón -arma emplea-

12 La fuente de esta información sobre el asno es YVES BonNeFoY, Mythologies, t. I, p. 432. Habría que notar, dicho sea de paso, que el asno se consideraba gran ayudante de Dionisio, enseñando a los hombres a podar la vid con delicadeza. (He consultado la traducción al inglés de Las ranas de ARISTÓFANTES en WHITNEY J. OAtes y Eugene O'NeILl, Jr., The Complete Greek Drama, t. II, 915-999.)

13 Véase Yves Bonnefoy, Mythologies, t. I, p. 433. Habría que añadir que el propio Sileno, como acompañante de Dionisio, también se asocia con los Misterios en diversos contextos, como se ve en unos frescos de Pompeya del primer siglo antes de Cristo, reproducidos en RICHARD CAVENDISH (ed.), Mythology: An Illustrated Encyclopedia (Nueva York, Rizzoli, 1980), p. 148.

${ }_{14}$ La lista de episodios de esta índole se extienden desde el ataque contra los molinos de viento de la Primera Parte (I, 8, pp. 128-30) hasta el «barco encantado» (II, 29, pp. 261-67) y el reto al tropel de los toros bravos (II, 58, pp. 480-81) de la Segunda. Vale la pena recordar el nexo entre la locura y la borrachera que establece JERÓNImo DE MONDRAGón, imitador del Elogio de la locura erasmiano, en su Censura de la locura humana y excelencias della, ed. ANTONIO Vilanova (Barcelona, Selecciones Bibliófilas, 1953 [1598]): 
da para guardar las viñas, tan estrechamente asociada con éstas que Quevedo se refiere al lanzón como «la insignia de viñadero» ${ }^{15}$.El acto de inundar su habitación en la venta de Juan Palomeque con vino también le rodea de una inequivocable aureola "báquica» ${ }^{16}$.

Por otra parte, tenemos al don Quijote no sólo cuerdo sino hasta sabio en tantas ocasiones, como reconocen los otros personajes ${ }^{17}$. Esa sabia locura puede derivarse del planteamiento erasmiano de la Moria, y también de muchas concepciones tradicionales de la locura de las que se derivan, sin duda, la del humanista holandés. Pero por otra parte, el fértil modelo de Sileno - borracho y fanfarrón pero dotado de grandes conocimientos- puede haber servido de acicate para sus fuerzas creadoras ${ }^{18}$.

Recordemos, también, que Sileno siempre se presenta como vie-

I que sean también locos los glotones, muéstralo Ateneo filósofo, con la respuesta que da a un problema acerca dello haze en nombre de otri diziendo: «Amigo Timócrates, atribuieron muchos a Baco la locura, porque los que sobradamente beven el vino, buélvense furiosos». Lo mesmo afirma Catón quando dize que la embriaguez es locura voluntaria, i Aristóteles, diziendo en sus Económicos que la embriaguez buelve locos a los hombres (p. 76).

15 Covarrubias define el «lanzón» como «Lanza corta y gruesa con hierro largo y ancho. Sirven para guardar la casa, las viñas y los melonares...» (consúltese la nota de MuRILLo, El ingenioso hidalgo..., I, 17, p. 211). La cita de Quevedo proviene de La Hora de todos y la Fortuna con seso, ed. de JEAN BoURG, PIERRE DuPONT y PIERRE GENESTE (Madrid, Cátedra, 1987): «Marte, don Quijote de las deidades, entró con sus armas y capacete, y la insignia de viñadero enristrada, echando chuzos, y a su lado, el panarra de los dioses, Baco, con su cabellera de pámpanos, remostada la vista, y en la boca lagar y vendimias de retorno derramadas, la palabra bebida, el paso trastornado, y todo el celebro en poder de las uvas» (pp. 149150). Los editores aclaran que «la insignia de viñadero» es, justamente, el «lanzón». A la luz de la problemática sileniana que estamos explorando, es de notar el nexo directo entre don Quijote y Baco que Quevedo establece aquí.

16 Es de notar que se ha conservado una estatua de bronce, perteneciente al Museo Arqueologico Nazionale de Nápoles, donde Sileno aparece sentado, precisamente, sobre un enorme cuero de vino. (Véase MichaEl Grant y JoHn HaZel, Who's Who in Classical Mythology, p. 366.)

17 Solamente en la Primera Parte encontramos los siguientes ejemplos: I, 30, p. 381 (un comentario del cura en la venta); I, 37, p. 466, y I, 38, p. 471 (la reacción de los que escuchan el discurso de las armas y las letras); I, 49, p. 577 (la reacción del canónigo ante el comportamiento y las palabras de don Quijote).

18 Para el muy probable vínculo entre la Moria de Erasmo y la concepción cervantina de la locura, consúltese la imprescindible obra de ANTONIO VILANOVA, Erasmo y Cervantes (Barcelona, Lumen, 1989). Es preciso recordar que el mismo Erasmo evoca la figura de Sileno en diversos contextos de su famoso Elogio (véase Elogio de la locura, trad. A. EsPINA [Barcelona, Planeta, 1987], pp. 27 y 46). A propósito del notable saber de Sileno, conviene considerar la posibilidad de que el magnífico discurso sobre la Edad de Oro, que surge pocos capítulos antes de la auto-asociación con Sileno (I, 11, pp. 155-57), re-cree paródicamente la historia narrada en la Egloga VI de Virgilio. 
jo. Sin embargo, incurre en un comportamiento que solemos asociar con la gente joven, o bien, inmadura. (Ser viejo borracho es grave justamente por la «inmadurez» que esto representa.) Aquí también percibimos el nexo directo con don Quijote. Puer senex por excelencia produce espanto entre sus familiares y sus vecinos por haberse lanzado al mundo con sus muchos años a cuestas para dedicarse al duro oficio de la caballería andante. La "borrachera» de la caballería andante es doblemente ofensiva por haberse dado en un hombre avanzado en años ${ }^{19}$.

$\mathrm{Y}$, sin embargo, no hay duda de que hay algo enormemente vital en este gesto. Recordemos que Sileno se asocia con Dionisio, ni más ni menos. Fue Sileno el que lo convirtió en ese dios cuyo regalo embriagador a los hombres emblematiza su primitiva energía indiferenciada. Sileno, ya viejo, lo acompaña en sus viajes a lugares distantísimos (hasta la India, se decía), manteniendo el ritmo frenético marcado por los otros miembros del séquito. Es decir, Sileno también proyecta una imagen de energía primordial, derivada en parte de su origen equino. Sileno nunca se distanció del todo, habría que añadir, de la erotomanía que definía a los sileni y a sus primos, los sátiros ${ }^{20}$.

También cabe preguntarnos si esta comparación tan atípica para don Quijote (esto es, por no derivarse de los libros de caballerías) no servirá de señal inconfundible para orientar al lector sobre la naturaleza de la obra en cuya lectura se ha embarcado. Recordemos que la auto-asociación con Sileno se da en la primera fase de

19 Para un astuto análisis del manejo paródico del tópico del puer senex en el Quijote, consúltese EDUARDo URBINA, "Don Quijote, puer-senex: un tópico y su transformación paródica en el Quijote», Journal of Hispanic Philology, 12, 1988, pp. $127-38$

20 A propósito de los sátiros y sileni como conjunto, Timothy Gantz, en Early Greek Myth: A Guide to Literary and Artistic Sources (Baltimore, The Johns Hopkins University Press, 1993), dice lo siguiente: «On what evidence we have [...], their amatory inclinations are the oldest part of their character, and it has even been suggested that their link with Dionysos is a subsequent development» (p. 138). (El mismo Erasmo se refiere a Sileno como «viejo verde» [Elogio..., p. 27].) Tomando este hecho en cuenta, es de notar que las circunstancias que llevan a la subida al asno de don Quijote, y su auto-asociación con Sileno, tienen que ver justamente con el comportamiento "rijoso" de Rocinante, a quien le viene «en deseo de refocilarse con las señoras facas" pertenecientes a los arrieros gallegos (I, 15, p. 191). Estas reaccionan mal ante "la fuerza» (ibid.) que Rocinante les aplica - tal como ocurre con las pobres ninfas que son típicas víctimas de sátiros y sileni-. Es más: el episodio que viene justo a continuación es el del encuentro nocturno entre don Quijote y Maritornes, esto es, donde el latente deseo sexual de don Quijote parece desbordarse (I, 16, pp. 202-04). Sobre la dinámica de los fuertes impulsos sexuales de don Quijote, consúltese CARroll Johnson, Madness and Lust: A Psychoanalytical Approach to "Don Quixote" (Berkeley/Los Angeles, University of California Press, 1983). 
la obra, la que está orientada más ostentosamente en la dirección de la comedia burda o «slapstick». Muchos estudiosos han comentado sobre la paulatina transición hacia una comicidad más fina y compleja en la obra, la cual destaca el hecho de que la concepción cervantina de su material iba "creciendo" en la medida en que su proyecto avanzaba.

Si Cervantes estuviera consciente del nexo entre Sileno y los géneros cómicos de la Antigüedad clásica, ¿qué mejor manera de «rotular» su obra - por lo menos dentro de su concepción primitiva- que asociar a su protagonista con esa figura clave de las comedias de sátiros? Es más: por los vínculos estrechos entre Sileno y Dionisio, el alegre dios de una risa que surge por el abundante consumo de vino en contextos colectivos, Cervantes también afilia a su protagonista con la cultura festiva popular. El sistema semiótico de ésta le servirá de base a Cervantes no sólo para la ideación de muchos episodios individuales de la obra, sino como infraestructura para la obra entera. Así, pues, en una especie de lapsus freudiano, si se quiere, don Quijote mismo deja caer la máscara de caballero andante que insiste en ponerse para manifestarse como el anciano risogénico del séquito de Dionisio ${ }^{21}$.

Ahora bien, estoy seguro de que algún lector estará a punto de recordarme que después de este episodio don Quijote le devuelve el asno a Sancho y que es éste el personaje que más estrechamente se afilia con el pequeño animal de carga. Lo cierto es que hay muchos aspectos del mismo Sancho que podrían relacionarse con Sileno. Tenemos, por ejemplo, su afición al vino (y su abuso de él). El vínculo con el emblemático asno no podría ser más ceñido. En muchas representaciones plásticas de Sileno, éste se representa como gordo $^{22}$. Los sileni, en su variante teatral, muchas veces se comportan como temorosos. Su papel de tonto-listo, y luego de tontosabio, también se pliega bien a la fundamental dualidad de Sileno ${ }^{23}$.

${ }^{21}$ Para diversos comentarios iluminadores sobre la relación entre el Quijote y la cultura festiva, véase MIJAIL BAJTín, La cultura popular en la Edad Media y Renacimiento; el contexto de François Rabelais, trad. J. ForCAT y C. CONROY (Madrid, Alianza, 1987); asimismo, AGUSTín REDONDo, «El personaje de don Quijote: tradiciones folklórico-literarias, contexto histórico y elaboración cervantina», Nueva Revista de Filología Hispánica, 29, 1980, pp. 35-59, y «Tradición carnavalesca y creación literaria: del personaje de Sancho Panza al episodio de Barataria», Bulletin Hispanique, 80, 1978, pp. 39-70. No nos olvidemos del hecho de que en un festejo montado en el Perú en 1607, "corrieron lanzas» dos individuos disfrazados de don Quijote y de Baco, con el segundo saliendo victorioso sobre el primero (véase FrANCISCO Rodríguez MARín, Estudios cervantinos [Madrid, Atlas, 1947], pp. 592-93). Los dos se ven, en fin, como acompañantes «naturales».

22 Véase, por ejemplo, la figura de Sileno en el «jarrón Borghese» (reproducido en la New Larousse..., p. 168).

${ }_{23}$ Sobre este aspecto fundamental de Sancho, consúltense los valiosos estudios 
A cierto nivel, es como si Cervantes escindiera el arquetipo de Sileno, depositando algunas características en don Quijote y otras en Sancho. (Recordemos, por ejemplo, que Sileno siempre se presenta como viejo mientras que Sancho no.) Don Quijote se sube al asno para establecer la conexión con Sileno, para luego "pasarle el bastón» a Sancho.

Ahora bien, si Sancho también queda afiliado con Sileno, y si su función es seguir a don Quijote en sus extravagantes andanzas, no cabe duda de que don Quijote termina ocupando el papel ya no del ayo del "alegre dios de la risa», sino del dios mismo. Ya señalé ese aspecto "dionisíaco» de la locura de don Quijote y de esa energía que la locura le infunde. La crítica también ha destacado ampliamente la contagiosidad de esa locura, que acaba reclutando a progresivamente mayores cantidades de gente (siendo la apoteosis los episodios de Barcelona). En ese sentido, don Quijote termina funcionando como una especie de Dionisio, sembrando el caos y las carcajadas adonde vaya.

Pero hay otra dimensión de la problemática sileniana que merece destacarse. El lector recordará que en El banquete de Platón hay la mención de unos silenos - esto es, cajas pintadas con feos sátiros, o silenos, cuyos interiores guardaban estatuas de dioses-. Alcibíades compara a su maestro Sócrates con una de estas cajas, esto es, para hacer resaltar el contraste entre la fea y risible forma exterior de su viejo maestro, muy aficionado al vino, por cierto, con el tesoro de sabiduría que se escondía detrás ${ }^{24}$. De manera característicamente jocosa, Rabelais recoge ese pasaje de El banquete (probablemente vía Erasmo) para describir la obra que está ofreciendo a sus lectores. O sea, detrás de la superficie ridícula de la historia de su Gargantúa se esconden verdades de alto valor ${ }^{25}$.

de Mauricio Molho, «Raíz folklórica de Sancho Panza», en Cervantes: raíces folklóricas (Madrid, Gredos, 1976), pp. 217-355, y de ANTHONY ClOSE, «Sancho Panza, Wise Fool», Modern Language Review, 68, 1973, pp. 344-357.

24 El pasaje en cuestión reza así (El banquete, $4 .^{\text {a }}$ ed., trad. L. GIL FERNÁNDEZ [Buenos Aires, Aguilar, 1962]):

«El elogio de Sócrates, señores, lo intentaré hacer en esta forma: mediante símiles. El tal vez creerá que servirán para ponerle en ridículo, pero el símil tiene por fin la verdad, no provocar la risa. Afirmo, en efecto, que es sumamente parecido a esos silenos que hay en los talleres de los escultores, que modelan los artífices con siringas o flautas en la mano y que al abrirlos en dos se ve que tienen en su interior estatuillas de dioses» (p. 125).

25 En la traducción al castellano de El Enquiridión de ERASMo, publicada en 1526, encontramos el siguiente pasaje (El Enquiridión o Manual del caballero cristiano, ed. DÁmAso Alonso [Madrid, Consejo Superior de Investigaciones Científicas, 1971]):

Digo más, que también se ha de guardar esta regla en la lición de toda escritura, que de dos partes está compuesta, es a saber, de sentido sim- 
¿Estaría consciente Cervantes de esas connotaciones del término «sileno»? ¿Querría insinuarnos que detrás de la fachada absurda del viejo hidalgo loco se esconde una insólita sabiduría? O bien, ¿querría - como Rabelais- establecer el nexo entre su obra y una

ple literal, de fuera, y de misterio encerrado de dentro, que son como cuerpo y ánima, que no haziendo hincapié en el literal, en este caso el principal respeto tengas al misterio que está dentro. Tales son quasi todas las escrituras de los poetas, y entre los filósofos las de Platón y de los que le siguen, y sobre todo están muy llenas de misterio las Escrituras Sacras del Testamento Viejo y Nuevo, que son en estos semejantes a aquellas figuras que le dizen los Silenos de Alcibiades [...], las quales so una cobertura vil y a sabiendas desfraçada encerravan otra cosa quasi divina (pp. 238-39).

En una nota a este pasaje (p. 239), Dámaso Alonso cita del artículo Sileni Alcibiadis de los Adagios de Erasmo, donde el humanista holandés dice esencialmente lo mismo. (Para una variante en el uso de esta idea, véase también el Elogio..., p. 46.) El pasaje de Rabelais reza así (Gargantúa, ed. Floyd Gray [París, Honoré Champion, 1995] [1542]):

Beuveurs tresillustres, et vous Verolez trespecieux (car à vous non à aultres sont dediez mes escriptz) Alcibiades ou dialoge de Platon intitué, Le bancquet, louant son precepteur Socrates, sans controverse prince des philosophes: entre aultres parolles le dict estre sembleable es Silenes. Silenes estoient jadis petites boites telles que voyons de present es bouticques des apothecaires pinctes au dessus de figures joyeuses et frivoles, comme de Harpies, Satyres, oysons bridez, lievres cornuz, canes bastées, boucqs volans, cerfz limonniers et aultres telles pinctures contrefaictes à plaisir pour exciter le monde à rire. Quel fut Silene, maistre du bon Bacchus: mais au dedans l'on reservoit les fines drogues, como Baulme, Ambre gris, Amomon, Musc, zivette, pierreries: et aultres choses precieuses. Tel disoit estre Socrates: parce que le voyans au dehors, et l'estimans par l'exteriore apparence, n'en eussiez donné un coupeau d'oignon: tant laid il estoit de corps et ridicule en son maintien, le nez pointu, le reguard d'un taureau: le visage d'un fol: simple en meurs, rustiq en vestimens, pauvre de fortune, infortuné en femmes, inepte à tous offices de la republique, tousjours riant, tousjours beuvant d'autant à un chascun, tousjours se guabelant, tousjours dissimulant son divin sçavoir. Mais, ouvrans ceste boyte: eussiez au dedans trouvé une celeste et impreciable drogue, entendement plus que humain, vertus merveilleuse, couraige invincible, sobresse non pareille, contentement certain, asseurance parfaicte, desprisement incroyable de tout ce pourquoy les humains tant veiglent, courent , travaillent, navigent et bataillent.

A quel propos, en voustre advis, tend ce prelude, et coup d'essay? Par autant que vous mes bons disciples, et quelques aultres foulz de sejour lisans les joyeux tiltres d'aulcuns livres de nostre invention comme Gargantua, Pantagruel, Essepinte, La dignité des braguettes, Des poys au lard cum commento etc., jugez trop facillement ne estre au dedans traicté que mocqueries, folateries, et menteries joyeuses: veu que l'ensigne exteriore (c'est le tiltre) sans plus avant enquerir, est communement receu à derision et gaudisserie. Mais par telle legiereté ne convient estimer les oeuvres des humains. Car vous mesmes dictes, que l'habit ne faict poinct le moyne: et tel est vestu d'habit monachal, qui au dedans n'est rien moins que moyne: et tel est vestu de cappe hespanole, qui en son couraige nullement affiert à hespane. C'est pourquoy fault ouvrir le livre: et soigneusement peser ce que y est deduict. Lors congnoistrez que la drogue dedans contenue est bien d'aultre valeur, que no promettoit la boite. C est à dire que les matieres icy traictées ne sont tant folastres, comme le titre au dessus pretendoit (pp. 45-47). 
de esas cajas con una exterior risible y un contenido trascendente ${ }^{26}$. En el caso de Rabelais, la alusión a la presencia de una dimensión seria detrás de la superficie ridícula puede haber sido una paródica tomadura de pelo.

¿Y en el de Cervantes? ¿Estaría presintiendo que su obra iba a superar, en la medida en que se iba elaborando, su condición burdamente cómica? Si ese fuera el caso, ¿no querría invitar a sus lectores a reflexionar sobre lo que puede hallarse más allá de las carcajadas suscitadas? Y ¿qué mejor manera de hacerlo que evocar la tradición de los silenos mencionados por Platón?

Sé que aquí empiezo a dejar atrás la escuela "funny book» que empezaba a apoyar al principio de este artículo para afiliarme con la escuela de interpretación "simbólica» de los románticos y posrománticos ${ }^{27}$. Pero de modo curioso, la evocación de Sileno parece apoyar las dos corrientes de lecturas que han caracterizado la recepción del Quijote. Por un lado, cristaliza el lado «slapstick» de la vis comica cervantina (especialmente en las primeras etapas de la obra); por otro, sirve como advertencia para sugerirnos que la obra tal vez esconda profundidades insospechadas ${ }^{28}$.

JAMES IFFLAND

Boston University

${ }^{26}$ El posible conocimiento de la obra de Rabelais por parte de Cervantes ha sido tema de discusión; véase Francisco Márouez VillanueVa, Fuentes literarias cervantinas (Madrid, Gredos, 1973), pp. 312-15 y 349. Lo que es indudable es que su obra sí se conocía en algunos círculos españoles, como nos recuerda FrANCISCO LAYNA RANZ, La disputa burlesca: origen y trayectoria, Criticón, núm. 64 (1995), p. 49.

27 Remito aquí al planteamiento de ANTHONY CLOSE en The Romantic Approach to "Don Quixote": A Critical History of the Romantic Tradition in "Quixote" Criticism (Cambridge, Cambridge University Press, 1978).

${ }_{28}$ La primera versión de este trabajo fue presentada como ponencia en el XIII Congreso de la Asociación Internacional de Hispanistas en Madrid en el verano de 1998. 